\title{
The Use of Gamification in Gastronomic Questionnaires
}

\author{
https://doi.org/10.3991/ijim.v14i02.11695 \\ David Prott $(\bowtie)$, Martin Ebner \\ Graz University of Technology, Graz, Austria \\ martin.ebner@tugraz.at
}

\begin{abstract}
Obtaining customer opinions and customer wishes is increasingly becoming an important part of any entrepreneurial activity for determining customer satisfaction and, subsequently, optimizing products and services as well as strengthen customer loyalty. In catering, there are several ways to capture the guest's satisfaction or dissatisfaction, as well as customer preferences and customer needs across different channels. One way to obtain a customer's opinion is to provide a digital online questionnaire. Unfortunately, the participation of guests in such surveys is usually low. In addition, many online questionnaires are aborted prematurely, and questions which require an individual text answer are often left unanswered. Gamification is a process to use game elements, game techniques and game mechanics from games in a different context in order to motivate and force people to do certain activities. This paper discusses whether the use of game elements in an existing gastronomical online questionnaire enhances the engagement of users and whether customer satisfaction remains the same. Based on an existing gastronomical online questionnaire from the company ITELL.SOLUTIONS $\mathrm{GmbH}^{1}$ a gamified questionnaire variant has been developed. Game elements such as points, badges, avatar, story, progress bar and instant feedback have been included.

The investigation showed that the use of gamification in questionnaires on open questions did not worsen the involvement of users. The customer satisfaction remained unchanged by the embedding of game elements too. Users of the expanded game questionnaire tended to give more precise and longer answers. The completion time also slightly increased for the gamified questionnaire. A direct comparison between the two variants of the questionnaire, showed that users preferred the design of the gamified questionnaire.
\end{abstract}

Keywords-Online questionnaire, gastronomy, customer satisfaction, gamification, game elements, ITELL.SOLUTIONS GmbH

\section{$1 \quad$ Introduction}

Computer games are increasingly accepted from a societal point of view [1] [2] [3] and also have the potential to appeal to certain incentives in humans in order to trigger high motivational readiness and performance [4] [5]. It is exactly this potential that

${ }^{1}$ https://itell.solutions (last accessed on 08 September 2019) 
should be used in everyday activities and in other game-free environments [6]. Gamification offers such an opportunity and is considered an innovative approach to positively impact the motivation and performance of people in different fields of application [3].

Studies have shown that the use of game elements in certain areas has a positive effect on the motivation and engagement of users, and that certain activities and problems of users can be carried out and solved more efficiently and conscientiously [7] [8] [9].

Deterding [10] stated the term gamification is "the use of game design elements in non-game contexts". In this definition, game design elements are referred to as specific and characteristic components of games [10]. Game design elements serve as a main ingredient of gamification [11] [12].

There are many different collections and categorizations of game design elements [3]. Very often game design elements such as points, badges and leader boards are associated with gamification [12].

Nowadays using gamification creates the expectation that the use of game design elements in certain fields of application has a positive effect on the commitment and performance of the users [3]. One possible application for gamification is data collection [3]. Especially in the catering industry data about customer satisfaction, needs and wishes can be collected via a digital online questionnaire [13]. One challenge with this kind of data collection is to attract potential participants and to motivate them to participate in the survey [14]. Another problem with this form of inquiry is the premature dropout rate of a questionnaire [15]. Reasons for that could be low motivation of the participants [16], length of the questionnaire or its uninteresting design [17]. Quite often questionnaires are perceived as boring, which does not immediately interrupt the questionnaire, but the problem is that the questions to be answered are read in a less concentrated manner and thus more inaccurate answers will be given [17]. There is still little research on gamification in this area of data collection. The following assumptions are discussed in this paper:

Hypothesis 1: When an existing gastronomic questionnaire is expanded with game elements, the engagement of the users increases.

Hypothesis 2: When an existing gastronomic questionnaire is expanded with game elements, customer satisfaction remains at least the same.

Based on these hypotheses the following research questions arise:

- How much does the processing time on the gamified questionnaire increase in median compared to the classical questionnaire?

- How does the response rate change by using a gamified questionnaire compared to the classical questionnaire?

- How much does the median of characters in text responses in the gamified questionnaire increase compared to the classical questionnaire?

- How much does the dropout rate of the gamified questionnaire decrease compred to the classical questionnaire?

- What is the difference in customer satisfaction when answering the gamified questionnaire compared to the classical questionnaire? 


\section{Research Design}

For the empirical study two-questionnaire versions, a classical and a gamified questionnaire, were used to compare the results of user responses within a certain period of time. The classical online questionnaire (Fig. 1), which has been specifically designed for the catering industry, was used and expanded with game elements to create a gamified questionnaire (Fig. 2).

The classical questionnaire consists of both closed and open questions as well as evaluation questions and includes a simple design. Furthermore, there are only few colors and animations used in this questionnaire [18]. For the creation of the gamified questionnaire, the existing procedure of the questionnaire was slightly modified and enriched with additional animations. For example, clicking on an answer briefly hides the selection button to give feedback to users that the answer has been selected. In order to get the full attention and concentration of the users, a design with many colors, with several illustrations and rounded edges was used. The gamified questionnaire used a story with multiple avatars, a highlighted selection indicator, points, and multiple badges as game design elements.

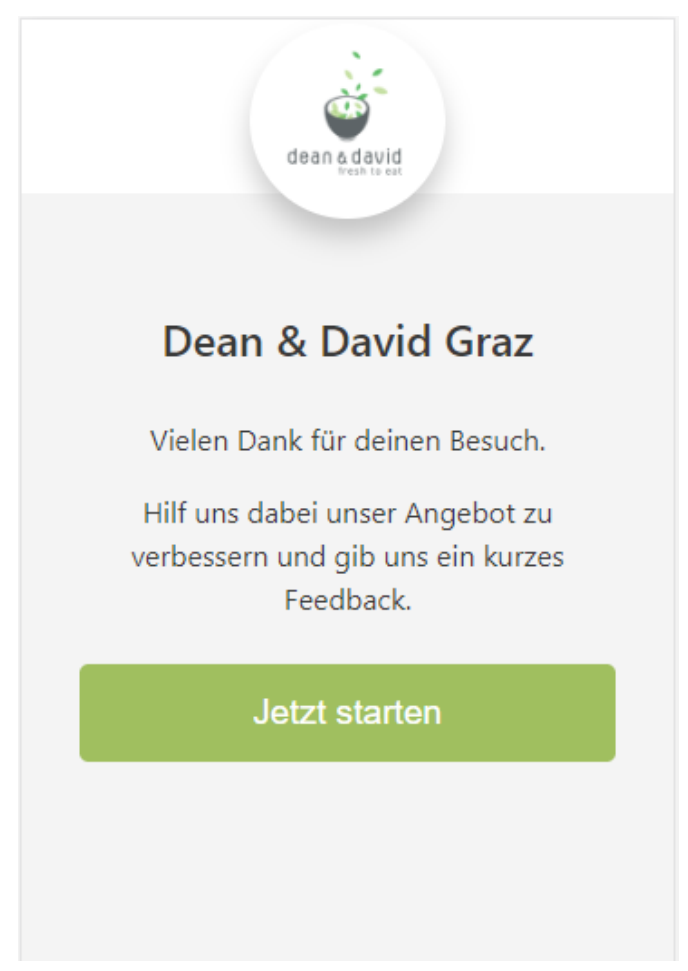

Fig. 1. Start page - Classical questionnaire. (Thank you for your visit. Help us to improve our offer and give us feedback.); translation of picture text. 


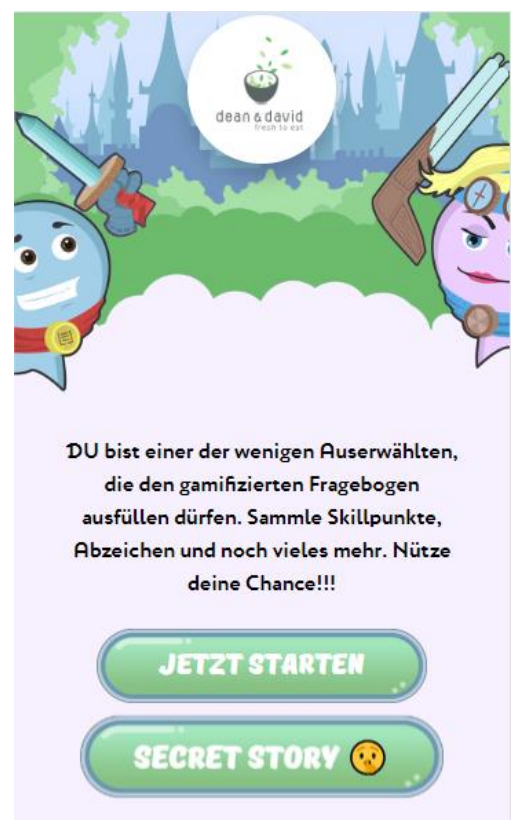

Fig. 2. Start page - Gamified questionnaire. (You are one of the few chosen to fill out the gamified questionnaire. Collect skill points, badges and much more. Take your chance!!!); translation of picture text.

\subsection{Development tools}

In order to program the online questionnaire, only open-source programs and libraries were used. Since the classical questionnaire was implemented in the form of a web application the front-end used the typescript-based framework Angular2. For backend development the Django framework3, a Python-based framework4, has been chosen. The relational database management system MariaDB5 was used to store the data. The embedded animations are based on CSS36 instructions.

\footnotetext{
${ }^{2}$ https://angular.io (last accessed on 08 September 2019)

${ }^{3}$ https://www.djangoproject.com (last accessed on 08 September 2019)

${ }^{4}$ https://www.python.org (last accessed on 08 September 2019)

${ }^{5}$ https://mariadb.org (last accessed on 17 September 2019)

${ }^{6}$ http://www.selfhtml5.org/ (last accessed on 08 September 2019)
} 


\subsection{Game design elements of the gamified questionnaire}

In the gamified questionnaire seven different game design elements were used. These cover the core drives such as meaning, creativity, performance, possession, and unpredictability and include both intrinsic and extrinsic motivational factors [19].

The following game design elements (Fig. 3) are included in the gamified questionnaire:

- Narrative - A story gives additional meaning to the activity to be performed and it has been scientifically proven that the human brain processes information much more easily, when it is embedded in a context [20].

- Avatar - Researches have shown that experiences a person makes with or through an avatar affect perception and behaviour outside the virtual world [21].

- Points - Gathering points additionally motivates a person to perform certain activities. For example, points are used as status icons to show other people how well they interact with the system [12], [22].

- Badges - Badges are visual representations of certain achievements [12]. Badges also have motivational factors. For example, they define goals that users can use to align themselves with, they indicate how the system is structured and show what opportunities users have in the system [23].

- Progress bar - Users strongly prefer applications with progress indicators, as they can estimate how long, for example, the computation time or load process of an application will take [24].

- Instant feedback - Instant feedback is the immediate feedback of the system during or after an activity by users. Users get information on how they are progressing in the system and can thus learn very quickly how to improve themselves in a gamified process [24].

- Glowing choice - Glowing choice helps users to move forward in an activity that uses visual representations to refer to the next action [19].

The ideas for the story and the associated avatars Figure 4 as well as the design in general, are the result of own experiences with game design elements. The game design items points and badges were chosen because they are used in most gamified applications [12]. The story and associated avatars were chosen to help explain why giving feedback is important to a business. The selection of glowing choice (Fig. 5) was made so that users get pre-generated answer possibilities in order to create an incentive to deliver a text response or a longer text response. 


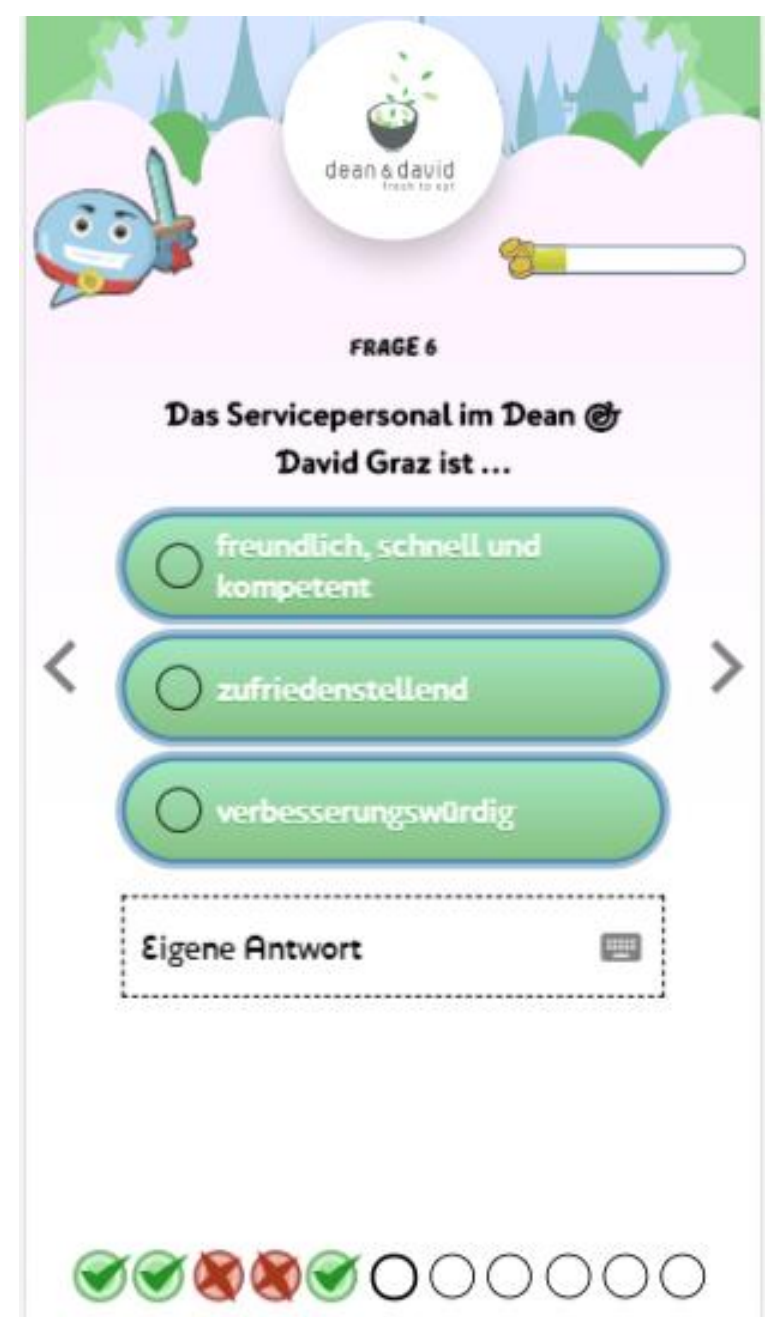

Fig. 3. Game design elements of the gamified questionnaire. (Question 6: The waitstaff at Dean \& David is); translation of picture text.

The progress bar and instant feedback (Fig. 6) were chosen to provide the user with feedback on his activity at all times and to motivate the user to complete the questionnaire. In addition, the selection of each game design element was made so that almost all core drives were used [19]. The inclusion of previous gamification research in the field of data collection also influenced the selection of elements such as points, rewards, progress or avatars [9] [26] [27]. In order to make measurability comprehensible only a maximum of seven game design elements was used. 


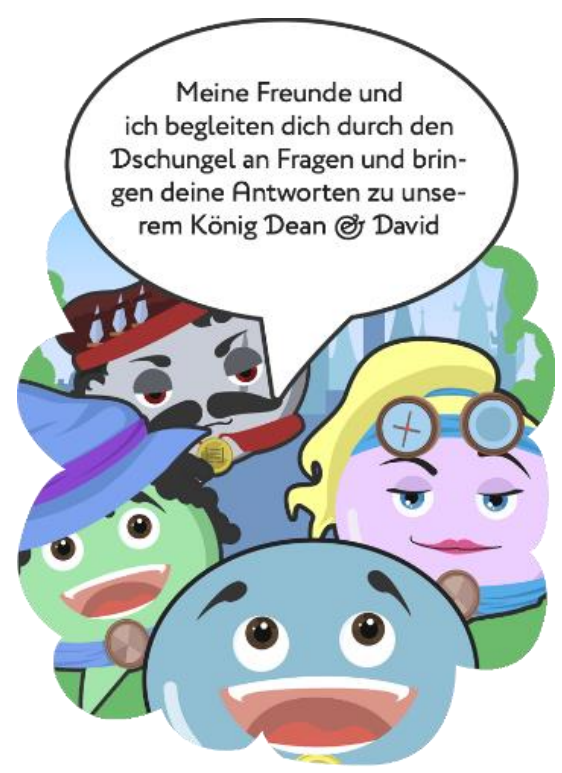

Fig. 4. Except from the story with avatars. (My friends and I will guide you through the jungle of questions and bring your answers to our King Dean \& David); translation of picture text.

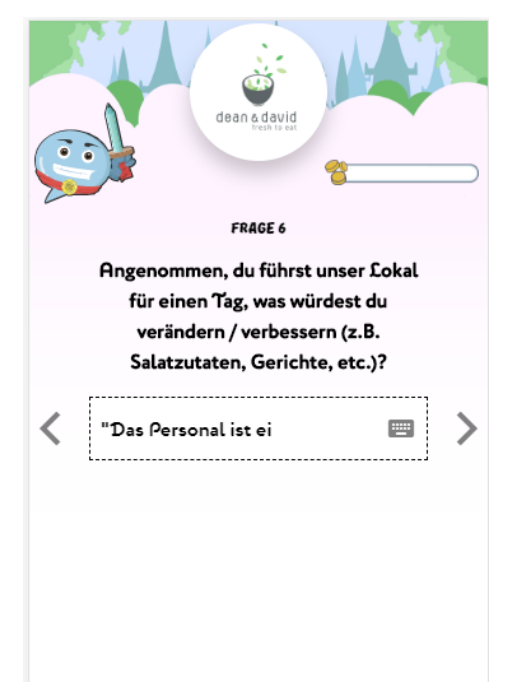

Fig. 5. Glowing Choice with open questions. (Suppose you manage our restaurant for a day, what would you improve? For example the ingredients for the salad, the food, etc.); translation of picture text. 


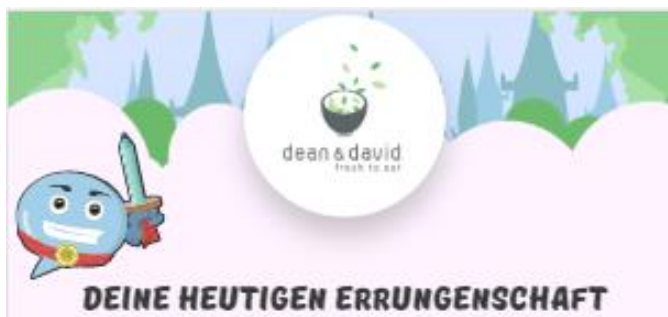

DEINE HEUTIGEN ERRUNGENSCHAFT

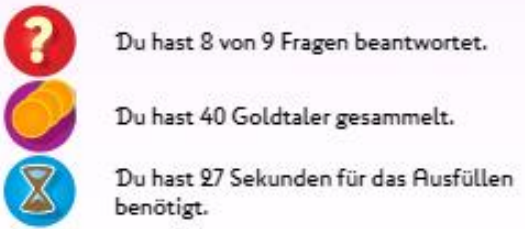

\section{DEIN BISHERIGER FORTSCHRITT}

21 Der König hat von dir 2 Feedbacks erhalten.

Deine Schatztruhe beinhaltet 45 Goldtaler.

Durch deinen Einsatz hast du 2 Orden verdient.

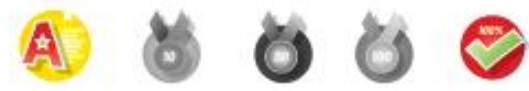

Story-Teller Fella Bronze Fella Silver Fella Gold Perfectionist

Fig. 6. Final Page with feedback on progress. (Your today's achievement. You have answered 8 out of 9 questions. You have collected 40 gold talers. You needed 97 seconds to complete the questionnaire. Your current progress. The king has received 2 feedbacks from you. Your treasure chest contains 45 gold talers. Your effort earned 2 medals.); translation of picture text.

\subsection{Sequence of the gamified questionnaire}

The structure and sequence of the gamified questionnaire has been slightly adjusted compared to the classical questionnaire. Due to the use of a story and the associated avatars the start screen was adjusted and other questions have been added to the avatar selection. The sequence of the gamified questionnaire is shown in Figure 7. 


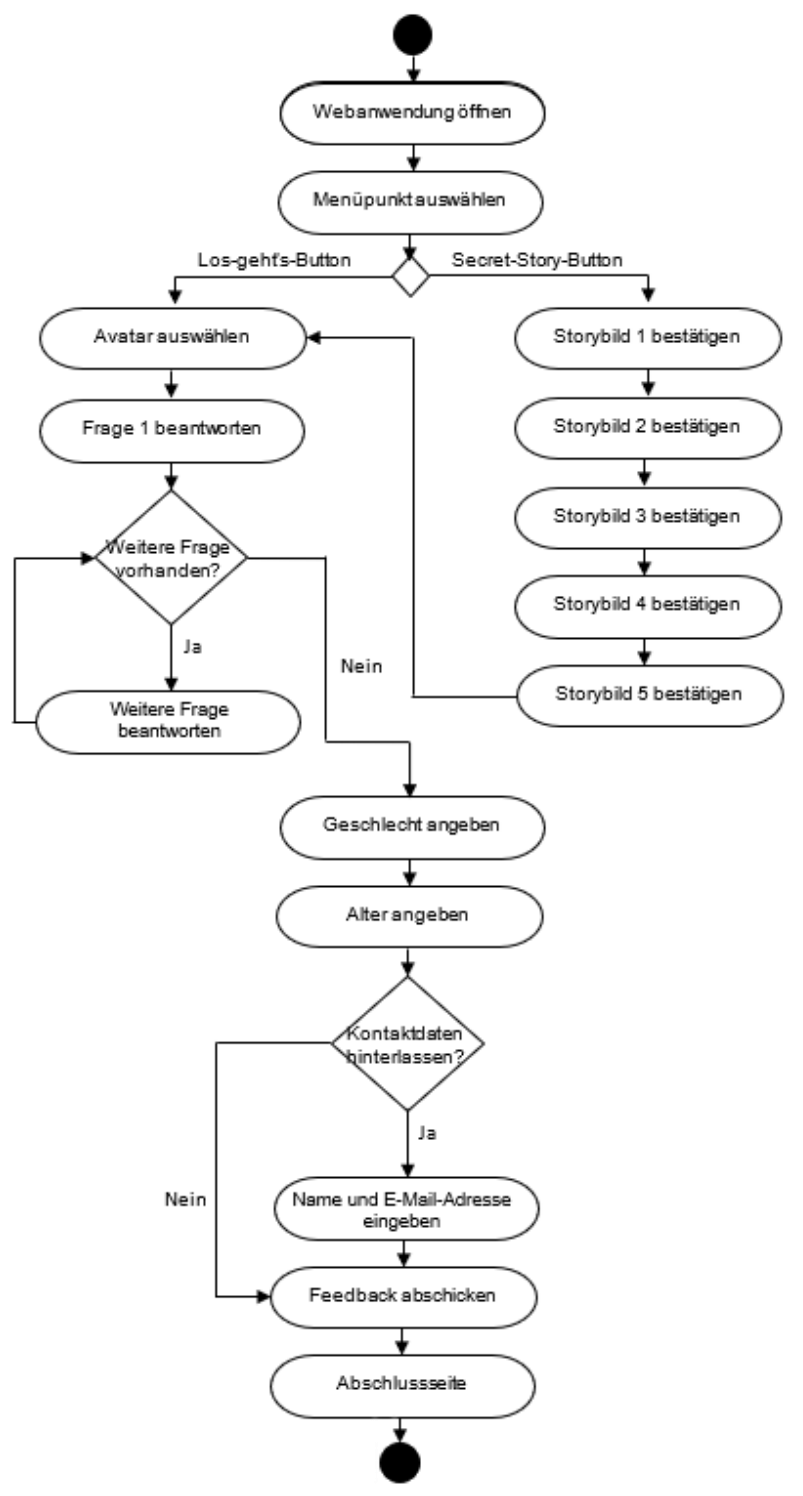

Fig. 7. Sequence of the gamified questionnaire

\subsection{Measurement}

Within a defined period of two months both versions of the questionnaire have been used in a selected catering company. Those people who consumed something, used the KUBO app (it's a customer loyalty app from the ITELL.SOLUTIONS company, which 
contains the online questionnaire)7 and additionally scanned the QR code on the bill were able to participate in the questionnaire. They got either the classical or the gamified feedback form. In order to guarantee the comparability of the two questionnaire versions in terms of structure and design, three additional questions were added. The additional questions evaluated the questionnaire in general, the used elements and an open question for obtaining suggestions for improvements regarding the questionnaire tool. All replies as well as the corresponding date and time of the accesses are stored in the database. The calculation of the questionnaire duration uses the access time and the completion time of a user answering the questionnaire. On the penultimate page (Fig. 7) there is a send button to mark the questionnaire as successfully completed, so that the abort rate can be determined to. The response rate can be determined as follows: Each invoice scan with the KUBO app automatically invokes one of the two questionnaire versions. Users then have the option to either fill in the questionnaire or to close it. The response rate thus results from the number of completed questionnaires compared to the number of scanned invoices.

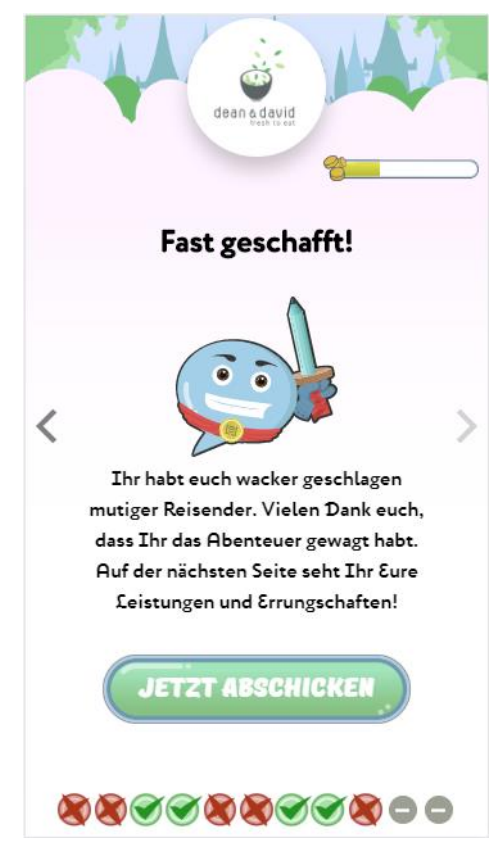

Fig. 8. Thank you text and button to send the questionnaire successfully.

(Almost done! You did very well. Thank you for daring to join us in the adventure. On the next page you can see your achievements.); translation of picture text

\footnotetext{
${ }^{7}$ https://kubo.rocks (last accessed on 08 September 2019
} 


\section{Evaluation}

The survey involved 150 people, who had invoked one of the two questionnaire versions. 141 of these questionnaires have been successfully sent in total.

\subsection{Demographics - Gender and age}

A total of 105 participants entered their gender, 36 persons remained anonymous and the remaining 9 persons could not be assigned because they prematurely quit the questionnaire and the gender-question is placed at the end of the questionnaire. $45 \%$ of all users are part of an age group which includes ages between 26 and 40. This group is the largest one in the empirical study. The second largest group is formed by persons between 41 and 55 years. This group represents $18 \%$ of all users.

\subsection{Processing time during the completion process of the questionnaire}

The following table 1 shows the median and the average of the processing time and as well as the minimum and maximum completion time for the different questionnaire type.

Table 1. Processing time of the classical questionnaire and gamified questionnaire

\begin{tabular}{|l|c|c|c|c|}
\hline \multicolumn{1}{|c|}{ Questionnaire } & Average & Median & Min & Max \\
\hline Classical & $00: 01: 04$ & $00: 00: 40$ & $00: 00: 10$ & $00: 19: 31$ \\
\hline Gamified & $00: 03: 25$ & $00: 01: 26$ & $00: 00: 15$ & $00: 48: 02$ \\
\hline
\end{tabular}

\subsection{Response rate}

The following table 2 shows the response rate for the classical and the gamified questionnaire. The response rate is the number of started questionnaire instances divided by the number of scanned bills.

Table 2. Response rate of the classical questionnaire

\begin{tabular}{|l|c|c|c|}
\hline Questionnaire type & $\begin{array}{c}\text { Return rate broken off } \\
\text { and completed feed- } \\
\text { backs }\end{array}$ & $\begin{array}{c}\text { Return rate with com- } \\
\text { pleted feedbacks }\end{array}$ & $\begin{array}{c}\text { Return rate (1x invoice } \\
\text { and 1x feedback from } \\
\text { the same user }\end{array}$ \\
\hline Classical & $21,01 \%$ & $19,49 \%$ & $27,46 \%$ \\
\hline Gamified & $14,89 \%$ & $14,22 \%$ & $28,09 \%$ \\
\hline
\end{tabular}

Since the two questionnaire versions were used in the live operation of a catering company, it is possible that participants call the questionnaire several times. Column 3 in table 2 takes this assumption into account. Accordingly, the rate changes. 


\subsection{Median of number of characters in text responses}

Table 3 shows the median and the average of the number of characters in open-text responses, the text reply rate, as well as the maximum and minimum number of characters in a text response for the classical and the gamified questionnaire.

Table 3. Evaluation of the number of characters in the classical and gamified questionnaire

\begin{tabular}{|l|c|c|c|c|c|c|c|}
\hline $\begin{array}{c}\text { Questionnai } \\
\text { re type }\end{array}$ & $\begin{array}{c}\text { Number of } \\
\text { feedbacks }\end{array}$ & $\begin{array}{c}\text { Number of } \\
\text { text } \\
\text { answers }\end{array}$ & $\begin{array}{c}\text { Text reply } \\
\text { quote }\end{array}$ & $\begin{array}{c}\text { Average of } \\
\text { used charac- } \\
\text { ters }\end{array}$ & $\begin{array}{c}\text { Median on used } \\
\text { characters }\end{array}$ & Max & Min \\
\hline Classical & 77 & 39 & $57,53 \%$ & 15,23 & 9 & 89 & 1 \\
\hline Gamified & 64 & 35 & $54,69 \%$ & 44,53 & 25 & 626 & 2 \\
\hline
\end{tabular}

Table 4 shows a brief excerpt of text responses including suggestions for improvement or wishes regarding the open question.

Table 4. Excerpt from text responses from the classical questionnaire and the gamified questionnaire

\begin{tabular}{|l|l|}
\hline \multicolumn{1}{|c|}{ Text answers from the classical questionnaire } & Text answers from the gamified questionnaire \\
\hline Put tofu back to your assortment & A little cheaper \\
\hline $\begin{array}{l}\text { Sometimes small things are forgotten. Double check } \\
\text { would be good. }\end{array}$ & Bigger portions \\
\hline Continue as it is! & Nothing \\
\hline Make the portions bigger. & No idea \\
\hline Many fruits. & Hz (meaningless) \\
\hline $\begin{array}{l}\text { Use all the ingredients in the salad that are also on the } \\
\text { list. }\end{array}$ & Hg (meaningless) \\
\hline $\begin{array}{l}\text { Give roasted nuts and seeds in all salads. More urban } \\
\text { drinks. }\end{array}$ & \\
\hline
\end{tabular}

\subsection{Dropout rate}

Table 5 and table 6 show the dropout rates for the classical and the gamified questionnaire.

Table 5. Distribution of dropouts and completions in the classical questionnaire

\begin{tabular}{|l|c|c|}
\hline & Frequency & Percent \\
\hline Valid conclusion & 77 & $93 \%$ \\
\hline Dropout & 6 & $7 \%$ \\
\hline Total & 83 & $100 \%$ \\
\hline
\end{tabular}


Table 6. Distribution of dropouts and completions in the gamified questionnaire

\begin{tabular}{|l|c|c|}
\hline & Frequency & Percent \\
\hline Valid conclusion & 64 & $96 \%$ \\
\hline Dropout & 3 & $4 \%$ \\
\hline Total & 67 & $100 \%$ \\
\hline
\end{tabular}

\section{6 (Dis) Satisfaction of guests with regard to the questionnaire}

For the determination of the satisfaction or dissatisfaction of the users and the finding of what the users particularly did liked or did not liked about the questionnaire tool, a questionnaire on the questionnaire tool, a question with multiple choice about the elements in the questionnaire and an open question about how to improve the questionnaire tool have been asked. Table 7. shows the customer satisfaction and the score for the classical and the gamified questionnaire.

Table 7. Customer satisfaction and rating to the questionnaire tool

\begin{tabular}{|l|c|c|}
\hline & Customer satisfaction & Rating questionnaire \\
\hline Classical questionnaire & 4.4 & 4.1 \\
\hline Gamified questionnaire & 4.4 & 4.1 \\
\hline
\end{tabular}

Table 8 and table 9 show the answer options for the classical and the gamified questionnaire and how often they were selected.

Table 8. Multiple choice of elements in the classical questionnaire

\begin{tabular}{|l|c|c|}
\hline \multicolumn{1}{|c|}{ Elements in the questionnaire } & \#Numner of entries & Percentage \\
\hline Usability & 22 & $38 \%$ \\
\hline Simpleness & 33 & $57 \%$ \\
\hline Design & 9 & $16 \%$ \\
\hline Speed & 15 & $26 \%$ \\
\hline Own words & 0 & $0 \%$ \\
\hline
\end{tabular}

Table 9. Multiple choice of elements in the gamified questionnaire

\begin{tabular}{|l|c|c|}
\hline \multicolumn{1}{|c|}{ Elements in the questionnaire } & \#Numner of entries & Percentage \\
\hline Avatars/Characters & 15 & $31 \%$ \\
\hline Story & 8 & $16 \%$ \\
\hline Design & 28 & $57 \%$ \\
\hline Animations & 15 & $31 \%$ \\
\hline Usability & 22 & $45 \%$ \\
\hline Own words & 1 & $2 \%$ \\
\hline
\end{tabular}

For the qualitative content analysis and in order to obtain research-relevant results from the answers to the open question, the evaluation is carried out according to Mayring [28]. 
In the classical questionnaire the question of possibilities for improvement was answered in 30 out of 77 cases, which corresponds to about $39 \%$. In the gamified questionnaire 39 out of 64 participants, that is about $45 \%$, provided textual answers for improvement. Compared to the classical questionnaire the percentage of text answers is thus 6 percentage points higher. For a better and more simple evaluation the text responses from the classical and gamified questionnaire were copied from the database and prepared in the form of tables.

The evaluation of the text responses has shown that very often only individual words, characters or incomplete sentences were present. When analyzing the text responses from the classical questionnaire, very often only one letter was used. The reason for this is probably that the users have assumed that the question is obligatory and can be answered by entering a sign. In the present text answers a grouping was made regarding the content. Text responses that contain only one character or that contain words that could not be attributed to the German dictionary have been removed from the list. Colloquial words or answers were accordingly circumscribed with other words, so that a grouping could be accomplished. A special concern during the transcription was that the statement is not distorted. Table 10 and table 11 show the text responses and the number of responses to the open question regarding improvements to the classical and gamified questionnaire tool.

Table 10. Key messages with the number of answers in the classical questionnaire

\begin{tabular}{|l|c|}
\hline \multicolumn{1}{|c|}{ Text answer } & Number of entries \\
\hline No improvements necessary & 8 \\
\hline Questionnaire too long & 3 \\
\hline QR-Code-Scanner does not work & 1 \\
\hline
\end{tabular}

Table 11. Key messages with the number of answers in the gamified questionnaire

\begin{tabular}{|l|c|}
\hline \multicolumn{1}{|c|}{ Text answer } & Number of entries \\
\hline Design & 11 \\
\hline Animations & 3 \\
\hline Questionnaire fits & 3 \\
\hline Display of text fields & 2 \\
\hline
\end{tabular}

\section{Discussion}

The evaluation of the individual results shows that the use of game elements in a gastronomical online questionnaire did not lead to any deterioration in the involvement of users. There are slight tendencies between the two questionnaire versions but due to the small number of participants no clear conclusions can be drawn here.

The processing time in the completion process of the gamified questionnaire tends to be longer in median and on average. One reason for this could actually be that the users have dealt with the individual questions for a longer time. Another possible reason could be that the sequence in the gamified questionnaire was enlarged by the story and the avatar selection. So especially the question about avatar selection took more time. 
Research question 1 can be answered as follows: The processing time for the gamified questionnaire increases by 46 seconds in the median compared to the classical questionnaire.

Regarding the response rate the classical questionnaire tends to perform better than the gamified questionnaire. Here is the assumption that users either give feedback on the first time they go to a restaurant and / or if their stay at the restaurant has been particularly positive or negative. Research question 2 can be answered as follows: The response rate has dropped from 5.27 percentage points to 14.22 percentage points compared to the classical questionnaire.

Regarding the text response rate for open questions about improving the experience the evaluation shows that the gamified questionnaire tends to have a higher quota than the classical questionnaire. In addition, the median and the average of the number of characters used in the gamified questionnaire are also higher than in the classical questionnaire. The assumption here is that the pre-generated answer option for open questions tends to encourage more users to write a text response. Research question 3 can be answered as follows: The median of the number of characters in text responses in the gamified questionnaire increased from nine to 25 characters compared to the classical questionnaire.

The dropout rate for both questionnaire versions is low and there are no big differences. The classical questionnaire had a dropout rate of $7 \%$ and and the gamified questionnaire had a dropout rate of $4 \%$. The dropout rate for both questionnaire versions are very low. One possible reason for this low dropout rate is probably that all questions in the questionnaire are optional. This means that not all questions need to be answered. If the completeness of the feedback data is considered, a correlation between the low abandonment rate and the optional questions is obvious.

In order to demonstrate an actual connection between the reduction of the dropout rate and the use of game design elements, a larger number of completed questionnaires will be needed. To answer the research question 4 the result is as follows:

The dropout rate of the gamified questionnaire is three percentage points lower than the classical questionnaire.

Regarding the customer satisfaction the evaluation showed that the use of game elements had no direct impact on customer satisfaction. The restaurant rating was 4.1 points for both the gamified and the classic questionnaire. Finally, the guests indicated that they tend to prefer the design of the gamified questionnaire rather than the classic questionnaire.

\section{Conclusion}

The use of gamification in the questionnaire showed that guests preferred to give more and more precise answers to open questions. In addition, it was also found that there was a tendency for more complete feedback to be sent to the gamified questionnaire. The processing time for the gamified questionnaire also tended to be slightly higher than for the classic questionnaire. It should be noted, that due to the small number of participants, there is still the need to use both questionnaire versions over a longer 
period of time or in several different companies in order to find more meaningful differences.

Furthermore, there is a need for research to find out why the guests tended to give longer answers in the gamified questionnaire or which game design elements influenced them by answering the questions. With regard to the processing time, it is necessary to research and analyze whether the avatar selection page had an influence on the processing time.

In order to make the individual game design elements more measurable it would be useful to conduct usability tests 8 in the form of Thinking Aloud Tests in order to obtain direct feedback from the users on the system. In addition, it is possible here to combine the usability feedback data from the test with the possibilities for improvement outlined in the database. The participants can express their wishes and suggestions for improvement in a very concrete way.

In the gamified questionnaire, the design was often perceived as particularly appealing. In this case, it could be clarified in the next step which parts of the design, such as color values, shape, etc., are viewed particularly positively.

According to the Hypothesis 1, the commitment of the users has not decreased. More users have tended to answer open questions and tend to use more characters. According to Hypothesis 2, the use of game elements also has no influence on customer satisfaction. There are slight tendencies that users prefer to fill out the gamified questionnaire. The processing time is slightly longer for the gamified questionnaire than for the classic questionnaire. In the comparison between the classical and the gamified questionnaire the customer satisfaction remained at least the same. That means that the evaluation of the gamified and the classical questionnaire results in a customer satisfaction of 4.4 points out of 5 possible points.

In summary, it can be stated that due to the small number of participants with 150 persons, only slight tendencies can be derived. The use of game elements in the questionnaire has shown that there has been no deterioration in the involvement of users. The game elements have also had no negative impact on customer satisfaction. A further result is that the guests prefer the design of the gamified questionnaire. It is important to mention that for the integration of game elements special care is required, so that accurate motivators and drives are triggered, which are essential for the achievement of goals.

\section{References}

[1] Sebastian, D. (2012). Gamification: designing for motivation. Interactions 19, 4 (July 2012), 14-17. https://doi.org/10.1145/2212877.2212883

[2] Wolters O. (2008). Elektronische Spiele: Wachstumsmarkt mit großer Wertschöpfung. In: Picot A., Zahedani S., Ziemer A. (eds) Spielend die Zukunft gewinnen. Berlin:Springer. https://doi.org/10.1007/978-3-540-78717-4_3

8 https://courses.isds.tugraz.at/hci/practicals/materials/de/taplan/taplan-de.html (last accessed on 08.09.2019) 
[3] Sailer, M. (2016). Die Wirkung von Gamification auf Motivation und Leistung. Wiesbaden:Springer. https://doi.org/10.1007/978-3-658-14309-1_5

[4] Garris, R., Ahlers, R., \& Driskell, J. E. (2002). Games, motivation, and learning: A research and practice model. Simulation \& gaming, 33(4), 441-467. https://doi.org/10.11 77/1046878102238607

[5] McGonigal, J. (2011). Reality is broken: Why games make us better and how they can change the world. London: Jonathan Cape.

[6] Strahringer, S., \& Leyh, C. (2017). Gamification und serious games. Grundlagen, Vorgehen und Anwendungen. Wiesbaden:Springer. https://doi.org/10.1007/978-3-658-16742-4

[7] Liu, Y., Alexandrova, T., \& Nakajima, T. (2011). Gamifying intelligent environments. Proceedings of the 2011 international ACM workshop on Ubiquitous meta user interfaces, Scottsdale. https://doi.org/10.1145/2072652.2072655

[8] Witt, M., Scheiner, C., \& Robra-Bissantz, S. (2011). Gamification of Online Idea Competitions: Insights from an Explorative Case. Paper presented at the 41. Jahrestagung der Gesellschaft für Informatik, Berlin.

[9] Musthag, M., Raij, A., Ganesan, D., Kumar, S., \& Shiffman, S. (2011). Exploring microincentive strategies for participant compensation in high-burden studies. Paper presented at the 13th international conference on Ubiquitous computing, Beijing. https://doi.org/10.11 45/2030112.2030170

[10] Deterding, S., Dixon, D., Khaled, R. \& Nacke, L. (2011). From Game Design Elements to Gamefulness: Defining "Gamification". Proceedings of the 15th International Academic MindTrek Conference: Envisioning Future Media Environments (p./pp. 9--15), New York, NY, USA: ACM. ISBN: 978-1-4503-0816-8. https://doi.org/10.1145/2181037.2181040

[11] Deterding, S., Khaled, R., Nacke, L., \& Dixon, D. (2011). Gamification Toward a Definition. Paper presented at the CHI 2011, Vancouver.

[12] Werbach, K., \& Hunter, D. (2012). For the Win: How Game Thinking Can Revolutionize Your Business. Philadelphia: Wharton Digital Press.

[13] ITELL.SOLUTIONS GmbH: „TeLLers - Das Feedback für die Gastronomie!“, In: Internseite ITELL.SOLUTIONS, 07.07.2017, https://tellers.co.at.

[14] Kotler, P., \& Bliemel, F. (2001). Marketing-Management - Analyse, Planung und Verwirklichung.10. edition. Pearson Studium.

[15] Knapp, F., \& Heidingsfelder, M. (1999). Drop-out-analyse: Wirkungen

[16] des Untersuchungsdesigns. In Reips Ulf-Dietrich et al., editor, Aktuelle Online-Forschung Trends, Techniken, Ergebnisse. Zurich:Online Press.

[17] Bosnjak, M., \& Batinic, B. (1999). Determinanten der Teilnahmebereitschaft an internetbasierten Fragebogenuntersuchungen am Beispiel Email. In Batinic B., Gräf L.; Werner A.; Bandilla W., editor, Online Research. Methoden, Anwendungen und Ergebnisse. Göttingen:Hogrefe. https://doi.org/10.1007/s11616-001-0180-5

[18] Graef, L. (1999). Optimierung von www-umfragen: Das online-preteststudio. In Batinic Bernad; Gräf Lorenz; Werner A., Bandilla W., editor, Online Research. Methoden, Anwendungen und Ergebnisse, pages 159-177. Göttingen:Hogrefe. https://doi.org/10.10 07/s11616-001-0180-5

[19] ITELL.SOLUTIONS GmbH: „TELLERS Survey”, In: Internetseite ITELL.SOLUTIONS, 01.09.2018, https://tlrs.at/ddg

[20] Chou, Y. (2015). Actionable Gamification. Beyond Points, Badges, and Leaderboards. Fremont:Octalysis Media. https://doi.org/10.17345/rio18.137-144

[21] Carey, B.: "This Your Life (and How You Tell It).”, In: Internetseite Nytimes, 22.05.2018, http://www.nytimes.com/2007/05/22/health/psychology/22narr.html?em\&ex $=1180065600 \&$ en $=4 \mathrm{~d} 426931 \mathrm{~b} 2330 \mathrm{fae} \& \mathrm{ei}=5087 \% 0 \mathrm{~A}$ 
[22] Yee, N., \& Bailenson, J.N. (2006). Walk a mile in digital shoes: The impact of embodied perspective-taking on the reduction of negative stereotyping in immersive virtual environments. Proceedings of PRESENCE 2006: The 9th Annual International Workshop on Presence. August 24 - 26, Cleveland, Ohio, USA.

[23] Zichermann, G., \& Cunningham, C. (2011). Gamification by Design: Implementing Game Mechanics in Web and Mobile Apps (1st ed.). O'Reilly Media, Inc..

[24] Antin, J., \& Churchill, E. (2011). Badges in Social Media: A Social Psychological Perspective. Gamification Workshop Proceedings.

[25] Myers, B. (1985). The importance of percent-done progress indicators for computer-human interfaces. ACM SIGCHI Bulletin. 16. 11-17. https://doi.org/10.1145/1165385.317459

[26] Marczweski, A.: "Feedback and Drivers in Gamification - Gamified UK", In: Internetseite Gamified UK, 07.01.2013, https://www.gamified.uk/2013/01/07/feedback-and-drivers-ingamification/.

[27] Downes-Le Guin, T., Baker, R., Mechling, J., \& Ruyle, E. (2012). Myths and realties of respondent engagement in online surveys. International Journal of Market Research, 54(5), 1-21. https://doi.org/10.2501/ijmr-54-5-613-633

[28] Rapp, A., Marcengo, A., Console, L., \& Semeoni, R. (2012). Playing in the wild: enhancing user engagement in field evaluation methods. Paper presented at the 16th International Academic MindTrek Converence, Tampere. https://doi.org/10.1145/2393132. 2393180

[29] Mayring P. (2010). Qualitative Inhaltsanalyse. Grundlagen und Techniken. 11. Auflage Weinheim:Beltz.

\section{$7 \quad$ Authors}

David Prott is with the Graz University of Technology, Graz, Austria. (david.prott@student.tugraz.at)

Martin Ebner is with the Social Learning Department at Graz University of Technology, Graz, Austria. (e-mail: martin.ebner@tugraz.at). As head of the Department, he is responsible for all university wide e-learning activities. He holds an Assoc. Prof. on media informatics and works also at the Institute for Information System Computer Media as senior researcher. For publications as well as further research activities, please visit: http://martinebner.atArticle submitted 16 October 2017. Published as resubmitted by the authors 29 November 2017.

Article submitted 2019-09-18. Resubmitted 2019-10-18. Final acceptance 2019-10-18. Final version published as submitted by the authors. 